\title{
Initial Surface Absorption of Pozzolan and Polymer Modified Mortar
}

\author{
Lau Si Kiong ${ }^{1}$ and Norsuzailina Mohamed $\operatorname{Sutan}^{2}$
}

\begin{abstract}
This study involves the investigation of water absoption of mortar modified with combinations of polymer and pozzolan by using initial surface water absorption test (ISAT). Since surface of mortar or concrete serves as medium that will be most easily penetrated by moisture that can cause corrosion of reinforcement bars that leads to durability problem, it is imperative to make it durable.Polymer additive and pozzolanic cement replacement used in this study was Styrene Butadiene Rubber (SBR) and Fly Ash (FA) respectively. Mixes were prepared with two water to cement ratios (w/c) of 0.3 and 0.4 with different combinations of 5\%, 7\% \& 10\% SBR additive and 10\%, 20\% and 30\% FA cement replacement. Results showed that modified mortar with combination of higher percentages of polymer additive and lower percentages of pozzolonic cement replacement have the lowest initial surface absorption rate compare to unmodified mortar. It can be concluded based on this study that high percentage of polymer addition and low percentage of pozzolanic cement replacement in mortar can enhance its resistance to water absorption.
\end{abstract}

Keywords: Polymer Modified Mortar, Styrene Butadiene Rubber (SBR), Fly Ash (FA), Initial Surface Absorption Test (ISAT).

\section{INTRODCTION}

$\mathrm{D}$ URABILITY of concrete structure is defined as its capability of to maintain a minimum performance level over a specific time when expose to any environment. In other words, durable concrete will retain its original form, quality and serviceability when exposed to its designated environment [1].The deterioration of concrete generally involves ingress of water or aggressive agents into concrete by physical or chemical processes. The mechanism of fluid transportation into concrete can be divided into three distinct groups which are summarized in Figure 1 [2].There are three main transportation processes in concrete: Absorption, Permeability and Diffusion. Absorption occurs when fluid ingress through capillary attraction. The absorption rate depends on the size and interconnectivity of capillary pores in concrete and the moisture gradient between concrete surface and its inner portion [2].The mechanism of transportation is an extremely complex interaction between permeation, material properties and environmental conditions as indicated in Figure 1. Since the surface of concrete/mortar serves as a medium that will be easily penetrated by moisture, it is imperative to make it durable. Previous studies showed that polymeric cement additive and pozzolanic cement replacement can make durable modified concrete or mortar [3-9]. The presence of polymer in mortar can decrease its permeability by the blocking of pores effect. Meanwhile, pozzolan in mortar reacts with by product of cement hydration Calcium Hydroxide $(\mathrm{CH})$ to produce more cementitious material called Calcium Silicate Hydrate (CSH) making mortar more impermeable [1]. Therefore the present study investigated the effect of different combinations of polymer and pozzolan namely Styrene Butadiene Rubber (SBR) and Fly Ash (FA) respectively on the surface absorption of mortar using initial surface absorption test (ISAT) [2]. BS 1881: Part 5 defines ISAT as a measurement of the rate of flow of water into concrete or mortar surface per unit area at fixed intervals under constant heat and temperature. The results can be used to indicate the quality of mortar in terms of resistance against water absorption of water that is directly related to durability. SBR is one of the synthetic polymer additives from aqueous polymer latex group used in polymer composite.

\footnotetext{
${ }^{1}$ Lau Si Kiong, Student of Civil Engineering Department, Universiti Malaysia Sarawak

${ }^{2}$ Norsuzailina Mohamed Sutan, Lecturer of Civil Engineering Department, Universiti Malaysia Sarawak (e-mail: msnorsuzailina@feng.unimas.my)
} 
The presence of polymer membranes gives a sealing effect that enhances the waterproofness or watertightness, increase air permeation and chemical resistance of polymer modified mortar [3] [4]. In other words, the addition of SBR into mortar can improve its resistance against water absorption [5][6]. Meanwhile, FA decreases the permeability by reducing bleed channels, capillary channels and void spaces inside the concrete and mortars through pozzolanic reaction [8][9].

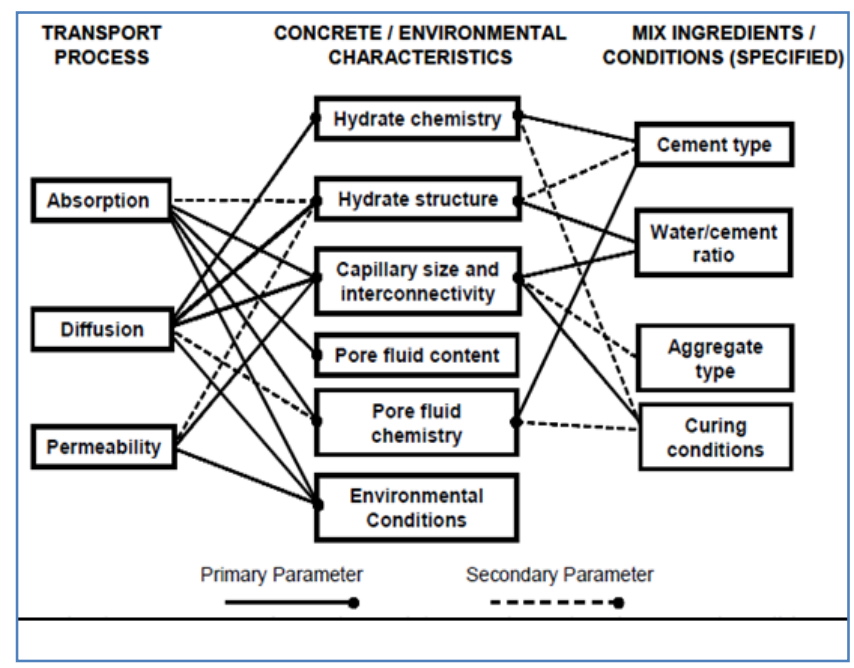

Figure 1: Interaction between material properties, environmental factors and transportation mechanisms of durability of concrete [2].

\section{MATERIALS AND METHODS}

\section{Materials}

Polymer and pozzolan used in this study were Styrene Butadiene Rubber (SBR) (Synthomer Grade 29Y46) from Synthomer UK and Fly Ash (FA) respectively. Ordinary Portland Cement (OPC) (ASTM Type 1 recognized by ASTM C150) manufactured by Cahaya Mata Sarawak Cement Sdn. Bhd (CMS) exceeded the quality requirements specified in the Malaysian Standard MS 52: Part 1: 1989 Specifications for Ordinary Portland Cement. The raw materials were clinker (90\%), limestone (5\%), and gypsum (5\%). The chemical and mineralogical characteristics of the OPC are given in Table 1.To study the combination effect of polymer and pozzolan on ISAT, mixtures were prepared with two water to cement ratios (w/c) of 0.3 and 0.4 with different combinations of 5\%, 7\% \& 10\% SBR additive and 10\%, 20\% and 30\% FA cement replacement. The mix proportions of all samples are shown in Table 2 and 3. The cement to sand ratio for all samples was 0.6.All samples that were casted into steel moulds of $150 \mathrm{~mm} \mathrm{X} 150 \mathrm{~mm}$ X $150 \mathrm{~mm}$ cubes.

Table 1: Chemical Composition of OPC.

\begin{tabular}{|c|c|c|c|c|c|c|c|c|c|c|}
\hline & $\mathrm{CaO}$ & $\mathrm{SiO}_{2}$ & $\mathrm{AL}_{2} \mathrm{O}_{3}$ & $\mathrm{Fe}_{2} \mathrm{O}_{3}$ & $\mathrm{SO}_{3}$ & $\mathrm{MgO}$ & $\mathrm{Na}_{2} \mathrm{O}$ & $\mathrm{K}_{2} \mathrm{O}$ & LOI & Others \\
\hline $\mathrm{OPC}$ & 63.0 & 21.79 & 5.75 & 3.25 & 2.35 & 1.97 & 0.5 & 0.28 & 1.0 & 0.11 \\
\hline
\end{tabular}

Table 2: Mix proportion of $0.3 \mathrm{w} / \mathrm{c}$

\begin{tabular}{|c|c|c|c|c|c|}
\hline \multirow{2}{*}{$\begin{array}{c}\text { Mix (1 unit) } \\
(150 \times 150 \times 150) \mathrm{mm}\end{array}$} & \multicolumn{5}{|c|}{ Weight $(\mathrm{g})$} \\
\hline & Water & Cement & Sand & SBR & FA \\
\hline \multicolumn{6}{|c|}{ Control (w/c 0.3) + Polymer (SBR) + Pozzolan (FA) } \\
\hline w/c0.3 SBR5\%FA10\% & 881.0588 & 2936.863 & 4894.793 & 146.835 & 326.3325 \\
\hline w/c0.3 SBR7\%FA10\% & 881.0588 & 2936.863 & 4894.793 & 205.595 & 326.3325 \\
\hline $\mathrm{w} / \mathrm{c} 0.3 \mathrm{SBR} 10 \% \mathrm{FA} 10 \%$ & 881.0588 & 2936.863 & 4894.793 & 293.7025 & 326.3325 \\
\hline w/c0.3 SBR5\%FA20\% & 783.1688 & 2610.563 & 4350.938 & 130.52 & 652.6325 \\
\hline w/c0.3 SBR7\%FA20\% & 783.1688 & 2610.563 & 4350.938 & 182.7475 & 652.6325 \\
\hline w/c0.3 SBR10\%FA20\% & 783.1688 & 2610.563 & 4350.938 & 261.04 & 652.6325 \\
\hline w/c0.3 SBR5\%FA30\% & 685.269 & 2284.23 & 3807.05 & 114.205 & 978.965 \\
\hline w/c0.3 SBR7\%FA30\% & 685.269 & 2284.23 & 3807.05 & 159.9 & 978.965 \\
\hline
\end{tabular}




\begin{tabular}{|c|c|c|c|c|c|}
\hline w/c0.3 SBR10\%FA30\% & 685.269 & 2284.23 & 3807.05 & 228.41 & 978.965 \\
\hline
\end{tabular}

Table 3: Mix proportion of $0.4 \mathrm{w} / \mathrm{c}$

\begin{tabular}{|c|c|c|c|c|c|}
\hline \multirow{2}{*}{$\begin{array}{c}\text { Mix }(1 \text { unit }) \\
(150 \times 150 \times 150) \mathrm{mm}\end{array}$} & \multicolumn{5}{|c|}{ Weight $(\mathrm{g})$} \\
\hline & Water & Cement & Sand & SBR & FA \\
\hline \multicolumn{6}{|c|}{ Control (w/c 0.4) + Polymer (SBR) + Pozzolan (FA) } \\
\hline w/c0.4 SBR5\%FA10\% & 1174.745 & 2936.863 & 4894.793 & 146.835 & 326.3325 \\
\hline w/c0.4 SBR7\%FA10\% & 1174.745 & 2936.863 & 4894.793 & 205.595 & 326.3325 \\
\hline w/c0.4 SBR10\%FA10\% & 1174.745 & 2936.863 & 4894.793 & 293.7025 & 326.3325 \\
\hline w/c0.4 SBR5\%FA20\% & 1044.225 & 2610.563 & 4350.938 & 130.52 & 652.6325 \\
\hline $\mathrm{w} / \mathrm{c} 0.4$ SBR7\%FA20\% & 1044.225 & 2610.563 & 4350.938 & 182.7475 & 652.6325 \\
\hline w/c0.4 SBR10\%FA20\% & 1044.225 & 2610.563 & 4350.938 & 261.04 & 652.6325 \\
\hline w/c0.4 SBR5\%FA30\% & 913.692 & 2284.23 & 3807.05 & 114.205 & 978.965 \\
\hline w/c0.4 SBR7\%FA30\% & 913.692 & 2284.23 & 3807.05 & 159.9 & 978.965 \\
\hline w/c0.4 SBR10\%FA30\% & 913.692 & 2284.23 & 3807.05 & 228.41 & 978.965 \\
\hline
\end{tabular}

\section{Initial Surface Absorption Test (ISAT)}

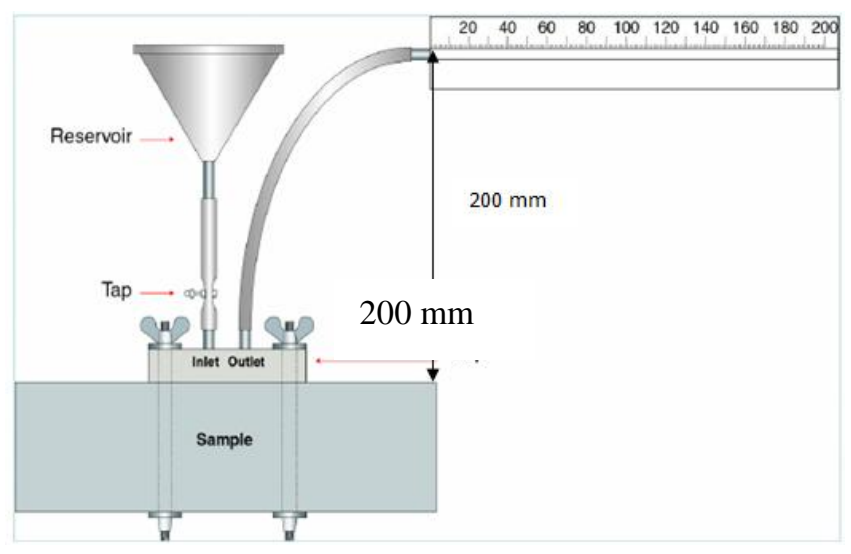

Figure 2: Setting of initial surface absorption test according to BS 1881: Part 5 and Part 208.

The initial surface absorption was measured through a known mortar surface area. The surface contact area was definite by a plastic cell sealed and clamped onto mortar surface. The volumetric flow rate was obtained by observing the length of flow along a capillary with a known dimension. The general arrangement of the test apparatus is shown in Figure 2 . The reservoir and capillary tube were assembled with support board of two stands. The capillary tube was installed up to 200 $\mathrm{mm}$ on top of the horizontal surface of specimen or $200 \mathrm{~mm}$ above the midlevel of vertical surfaces to create pressure on the surface of mortar. All apparatus were washed in a soap solution to minimize the surface tension. A circular cap with a surface area of at least $5000 \mathrm{~mm}^{2}$ was clamped tightly onto the mortar surface and filled with distill water from a reservoir. The other end of the tube was connected to a horizontal, calibrated glass capillary tube. 


\section{RESULTS AND DISCUSSION}

Figure 3 and 4 show the ISAT rate for mortar with $0.3 \mathrm{w} / \mathrm{c}$ and $0.4 \mathrm{w} / \mathrm{c}$ respectively. Both graphs show ISAT rate gradually decreased with time as sample was becoming saturated with water. It can also be seen that the ISAT rate for $0.4 \mathrm{w} / \mathrm{c}$ mortar is lower than $0.3 \mathrm{w} / \mathrm{c}$ mortar. This means that $0.3 \mathrm{w} / \mathrm{c}$ mortar has more capillary or void compared to $0.4 \mathrm{w} / \mathrm{c}$ mortar due to due to lack of water for full hydration.

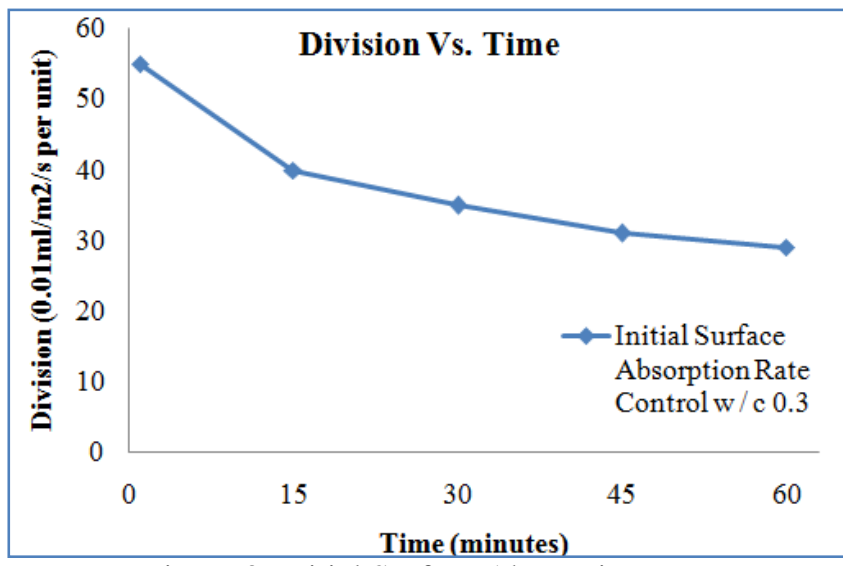

Figure 3: Initial Surface Absorption Rate of $0.3 \mathrm{w} / \mathrm{c}$

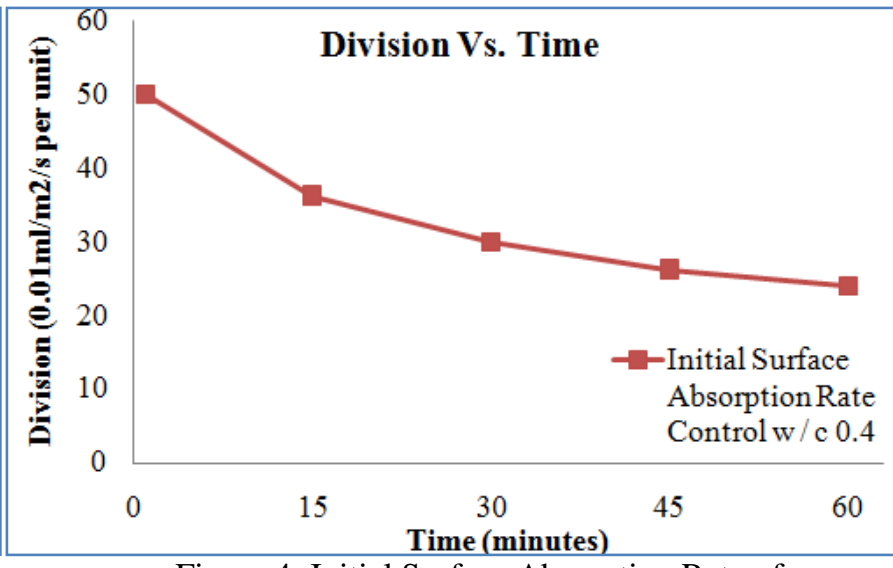

Figure 4: Initial Surface Absorption Rate of $0.4 \mathrm{w} / \mathrm{c}$

Figure 5 shows the ISAT results for all combination modified mortar of $0.3 \mathrm{w} / \mathrm{c}$.

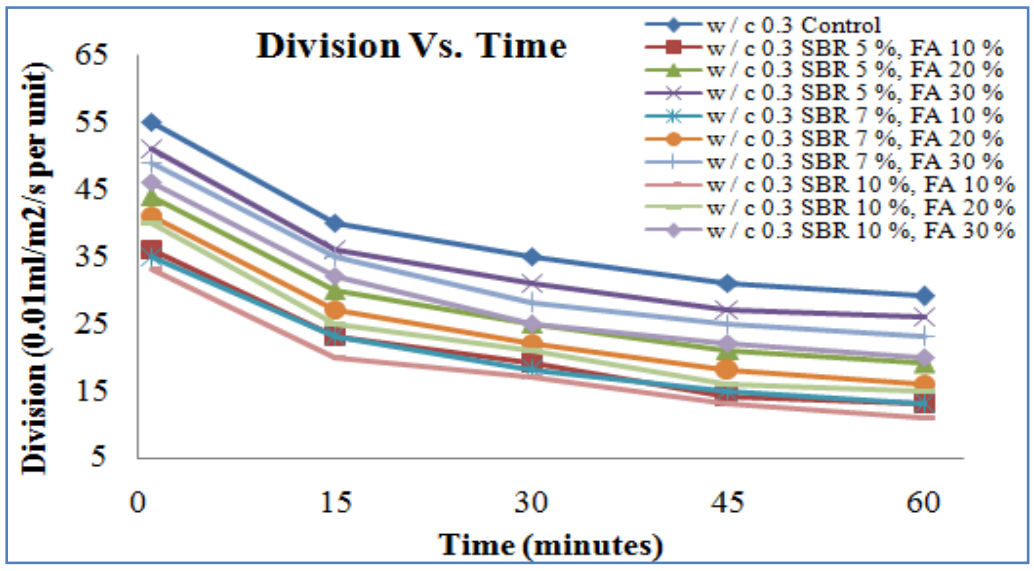

Figure 5: Initial Surface Absorption Rate for different combination of SBR and FA modified mortar of 0.3 w/c.

Data were presented in terms of ISAT rate in $0.01 \mathrm{ml} / \mathrm{m}^{2} / \mathrm{s}$ per unit versus time in minutes. The data were taken every 15 minutes in order to see the pattern starting from 1 minute, 15 minutes, 30 minutes, 45 minutes, and 60 minutes. Based on Figure 5, $0.3 \mathrm{w} / \mathrm{c}$ mortar has the highest ISAT rate meanwhile modified mortar of $10 \% \mathrm{SBR}$ and $10 \% \mathrm{FA}$ of $0.3 \mathrm{w} / \mathrm{c}$ has lowest ISAT rate. This shows that the best combination of both polymer and pozzolan in modified mortar was the one with highest SBR and lowest FA content. From the graph, it is also shown that the ISAT rate for specimens were decreasing from specimen that have lower SBR (5\%) and higher FA (30\%). Besides, ISAT rate decreased with time for all specimens. These entire patterns can also be observed in Figure 6 for all $0.4 \mathrm{w} / \mathrm{c}$ samples. The combination of polymer and pozzolan has improved the 0.3 mortar by making it water resistance. Polymer block the pores and the presence of FA caused pozzolanic activity in which helped decrease the permeability by reducing bleed channels, capillary channels and void spaces inside the mortar. 


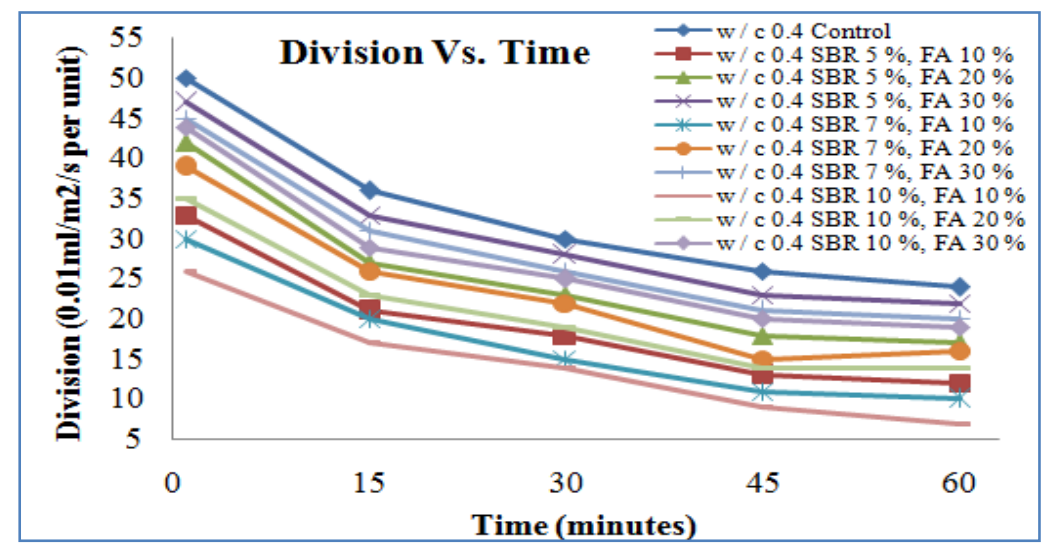

Figure 6: Initial Surface Absorption Rate for mortar of $0.4 \mathrm{w} / \mathrm{c}$ with different combination of SBR and FA.

\section{CONCLUSION}

Modified mortar showed better water absorption resistance compared to unmodified mortar. The specimen with higher addition of SBR and lowest replacement of FA gave better resistance against water absorption compared to the other combination. As a conclusion, higher addition of SBR into the mortar will improve the permeability of mortar. However lower amount of FA was favorable since the amount of water available for hydration during curing period increases as the amount increases. It can be concluded based on this study that high percentage of polymer addition and low percentage of pozzolanic cement replacement in mortar can enhance its resistance to water absorption.

\section{ACKNOWLEDGMENT}

The authors wish to acknowledge University Malaysia Sarawak for supporting this work under the FRGS/03(04)/772/2010(53) grant.

\section{REFERENCES}

[1] Bhattacharjee, B. (2008). Module 7 Lecture -1: Durability of Concrete. Department of Civil Engineering, IIT Delhi

[2] Dhir, R. K, McCarthy, M. J. \& Newlands, M. D. (1997) Challenges In Designing Concrete Durability: A Sustainable Approach. Concrete Technology Unit. University of Dundee, UK

[3] Ohama, Y. (1997). Recent Progress In Concrete - Polymer Composites.

[4] Ohama, Y. (1994). Classification of Concrete - Polymer Composities.

[5] Boonpradit, P. S. A. N. (2006). Use of Liquid Polymer to Prevent Moisture Loss during Curing and to Improve Watertightness at the Hardening Stage. Thammasat Int. J. Sc. Tech. 11(2): 41-46.

[6] Radonjanin, R. (1998). Experimental Research On Polymer Modified Concrete. ACI Material Journal 95.

[7] Z.Su, K. S., J.M.J.M Bijen, H.M. Jennings, \& A.L.A. Fraaij (1996). The Evolution of Microsructure in Styrene Acrylate for Polymer-Modified Cement Pastes at Early Stage of Cement Hydration. Advanced Cement Based Material 3: 87-93

[8] Mehta, P.K. (n.d.). High - Performance, High - Volume Fly Ash Concrete For Sustainable Development. International Workshop on Sustainable Development and Concrete Technology. 